\title{
Optimization of Physical Parameters of Discrete Element Method for Blast Furnace and Its Application to the Analysis on Solid Motion around Raceway
}

\author{
Shungo NATSUI, Shigeru UEDA, Masashi OIKAWA, Zhengyun FAN, Junya KANO, Ryo INOUE \\ and Tatsuro ARIYAMA
}

Institute of Multidisciplinary Research for Advanced Materials, Tohoku University, Sendai 980-8577 Japan.

(Received on March 5, 2009; accepted on April 30, 2009)

\begin{abstract}
Analysis of solid motion in the vicinity of raceway of the blast furnace has been carried out by discrete element method (DEM). The physical properties of particle for DEM calculation are important factors to simulate precisely the solid motion in the blast furnace. In order to represent the feature of burden such as coke in the lower part of the blast furnace, the rolling friction was cautiously determined. Through the simulation results, it was found in the result of simulation that the contact friction and the rolling friction have a great influence on the solid motion especially in the lower part of blast furnace. In the present study, the contact friction of actual coke used for blast furnace was experimentally measured. The optimum combinations of contact and rolling friction coefficients were derived from the angle of repose obtained from the DEM. On the basis of the physical parameters optimized for blast furnace, the solid motion around the raceway where the ununiformity was remarkable in blast furnace was analyzed. The influence of variation of raceway is examined to clarify the motion of coke in the lower part of blast furnace. According to the results, it was found that the height of deadman varied with changing the depth of raceway. The interval of tuyeres seriously influences on the ununiformity of solid motion in the direction of circumference. Owing to DEM based on the optimized physical parameters, three dimensional analysis of solid motion containing the ununiform region became possible.
\end{abstract}

KEY WORDS: ironmaking; modeling; discrete element method; blast furnace; raceway; tuyere.

\section{Introduction}

Numerical simulation helps to understand the behaviors of burden in the blast furnace. The mathematical models for the blast furnace operation based on the equations of mass, momentum, heat balances and reaction kinetics have been already developed. ${ }^{1,2)}$ Although those continuum-based models are well developed, they can not deal discontinuance phenomena such as the unstable slip of burden in blast furnace and the ununiform solid movement nearby the raceway. The information on these phenomena are so important to attain the stable blast furnace operation especially in the large blast furnace under low reducing agent. ${ }^{3)}$ In the discrete element method (DEM), the equations of motion for every particle are derived from the contact force. Therefore, it is possible to simulate the discontinuance phenomena and the ununiform motion in the blast furnace with applying DEM.

Firstly, the optimization of DEM was carried out to perform smoothly the practical calculation for blast furnace and to secure high accuracy of solid motion. Generally, since the calculation of DEM needs large resource of computer, the condition of simulation is restricted by the power of computers. The particle calculated in original DEM is basically supposed to be sphere. ${ }^{4)}$ Meanwhile, the shape of coke and sinter for blast furnace are irregular. Therefore, the shape factor of the burden should be cautiously installed into DEM. Since the shape factor of the particle causes the increase in the enormous load of computation, some ideas for addition of shape factor such as rolling friction based on sphere particle ${ }^{5-8)}$ and cluster of sphere parti$\mathrm{cle}^{9)}$ were proposed. However, the solid motion is influenced by the rolling friction; originally the rolling friction calculated from the elastic deformation. It is unsure that the rolling friction actually corresponds to the shape of coke. Cluster of sphere particle can partially represent the shape of irregular particle, meanwhile it also increases the load of computation.

In the present study, some procedures were adopted to represent the solid motion with the factors of physical properties, namely, shape of particle, roughness of surface and friction coefficient of material. In order to satisfy these factors simultaneously, the rolling friction and the contact friction were systematically combined. The contact friction was measured with sliding pieces of coke on coke bed or bricks. Using the measured range of contact friction coefficient, the rolling friction coefficient was derived by simulating angle of repose with DEM. 
On the basis of the optimized DEM parameters for blast furnace, the solid motion of coke around the raceway where the ununiformity was noticeable was analyzed. Some experiments on solid motion around raceway had been carried out by cold model to understand solid motion in the vicinity of raceway. ${ }^{10-14)}$ Motion of particles in quasi-stagnant region on deadman is well observed. ${ }^{10)}$ The relationship between depth of raceway, shape of deadman and solid motion in actual blast furnace is also disucussed. ${ }^{14)}$ These results from cold models show influences of raceway on solid motion, however consumption of coke in raceway is difficult to be represented. By the mathematical simulation of the solid motion with a cold model, the relationship between shape of raceway and instability of that was discussed. ${ }^{6}$ However, these information are limited to two dimensional motion near the raceway. In this region, the solid motion is complicated, because the stagnant and active zone coexists three dimensionally. Understanding behavior of solid motion in this region is very important especially that in the large blast furnace under low reducing operation. In the present study, the solid motion in the vicinity of the raceway was analyzed in the three dimensional structure through DEM optimized for blast furnace. The arrangements of the raceway such as the variation of the shape, size and interval of raceway were examined.

\section{Application of DEM for Blast Furnace}

\subsection{Fundamental Equations of DEM}

DEM was employed to simulate the three dimensional motion of coke in the vicinity of raceway of the blast furnace. Concept of interactive force between particles calculated in DEM is illustrated in Fig. 1. A model of contact force which consists of the Voigt model including a spring and dashpot was used for the DEM. The contact force, $F_{\mathrm{n}}$ : normal and $F_{\mathrm{s}}$ : shear are derived as

$$
F_{\mathrm{n}, i j}=\left(K_{\mathrm{n}} \Delta u_{\mathrm{n}, i j}+\eta_{\mathrm{n}} \frac{\Delta u_{\mathrm{n}, i j}}{\Delta t}\right)
$$

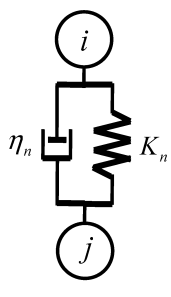

(a) Normal force

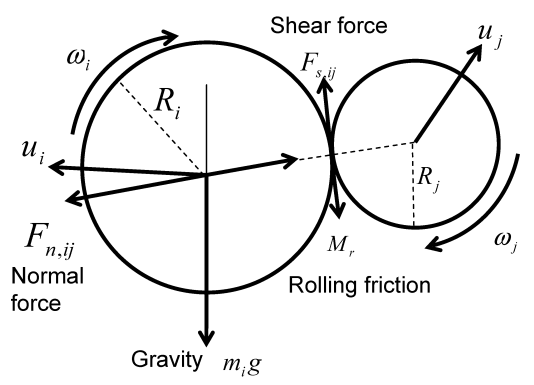

(c) Interactive between two particles
Fig. 1. Interactive forces between two particles in DEM. and, the smaller force of

$$
F_{\mathrm{s}, i j}=\left(K_{\mathrm{s}}\left(\Delta u_{\mathrm{s}, i j}+\Delta \varphi_{i j}\right)+\eta_{\mathrm{s}} \frac{\left(\Delta u_{\mathrm{s}, i j}+\Delta \varphi_{i j}\right)}{\Delta t}\right) t_{i j} \ldots
$$

or

$$
F_{\mathrm{s}, i j}=\mu\left|F_{\mathrm{n}, i j}\right| t_{i j}
$$

Where, $K, \eta, \mu, \mathrm{n}$ and $\mathrm{s}$ denote stiffness, damping coefficient, contact friction coefficient, normal and tangential, respectively. $\Delta u$ and $\Delta \varphi$ are a relative translational displacement of gravitational center between particle $i$ and $j$, and a relative displacement at the contact point due to rotation of particles, respectively. $n_{i j}$ and $t_{i j}$ are unit vector from particle $i$ to $j$ in normal and tangential directions. The spring and dashpot represent the elastic and plastic nature of particles, respectively. $K_{\mathrm{n}}$ and $K_{\mathrm{s}}$ derived from Young's modulus $(E)$ and Poisson's ratio $(P)$ as

$$
K_{\mathrm{n}}=\frac{2 b \cdot E}{3\left(1-P^{2}\right)}
$$

and

$$
K_{\mathrm{s}}=\frac{K_{\mathrm{n}}}{2(1+P)}
$$

where, $b$ denotes radius of contact circle. In the tangential direction, slider which expresses the maximum friction force on particles, is installed as Eq. (3).

The motion of particle is derived from integration of the normal and tangential force, $F$ and $M$

$$
m \frac{d u}{d t}=\sum F
$$

and

$$
I \frac{d \omega}{d t}=\sum M
$$

Where, $m, I$ and $\omega$ denote the mass of the particle, velocity, moment of inertia and the angular velocity, respectively.

\subsection{Condition of Calculation}

Solid motion in a blast furnace with $5000 \mathrm{~m}^{3}$ inner volume and 40 tuyeres is object for the DEM simulation. Simulation is limited to a part of blast furnace as shown in Fig. 2. That is the region from $5 \mathrm{~m}$ over of the tuyere level to $1 \mathrm{~m}$ below of that. The particles are charged from $9 \mathrm{~m}$ over the tuyere level, that is $4 \mathrm{~m}$ higher than analyzing volume. Since movement of particle at charging causes ununiformity in upper part of packed bed. The motion of particles over $5 \mathrm{~m}$ from tuyere level was excluded from analysis. The radiuses of the balst furnace of tuyere level and shaft and angle of bosh are 7.8, $8.6 \mathrm{~m}$ and 78 degree, respectivery. The angle of sector form is 18 degree, and the both side of flat walls are supossed to be connected with periodical boundary condition as shown in Fig. 2(b). Two tuyeres are located on the flat wall and one is on center of curved wall. In order to avoid self contact of particle, cylindical wall with $1.2 \mathrm{~m}$ diameter and no friction was pleased at center of the blast furnace. 
(a)


Fig. 2. Condition in the simulation of solid flow in blast furnace around raceway. (a) Dimension, (b) boundary condition.

The raceway shape is assumed to be the ellipsoidal shape with $1.5 \mathrm{~m}$ in length and $1.0 \mathrm{~m}$ in width. The particle entrained the raceway area is uniformly vanished for an aimed interval. The stock line is placed at $8 \mathrm{~m}$ over the tuyere level. The packing material was set to only coke, because this calculation focused on the lower part of the blast furnace. Although the actual diameter of the coke used in the blast furnace is about $0.05 \mathrm{~m}$, the particle diameter in this calculation was set to $0.2 \mathrm{~m}$ so as to accelerate the calculation.

Generally, the gas flow has an influence on the burden descending especially at the throat. Regarding the lower part of blast furnace, it is not clear that the gas flow has a great influence on the burden descending. In the present study, the physical mechanism through the interaction among the particles is regarded as of major importance for analyzing the burden descending.

\section{Physical Property of Particle for Representing the Coke}

\subsection{Shape Factor of Particle}

Since the packed material, that is, coke used in ironmaking is irregular shape, the shape of coke should be considered. The particle considered in the DEM is sphere. In order to represent shape, rolling friction is installed. Original rolling friction represents the energy dissipation mechanism with the elastic deformation at the contact point. ${ }^{15)}$ Rolling friction; $M_{\mathrm{r}}$ is defined as a function of rolling friction coefficient, such as,

$$
M_{\mathrm{r}}=\frac{3}{8} \alpha \cdot b\left|f_{\mathrm{n}}\right|
$$

where, $\alpha, b$ and $f_{\mathrm{n}}$ are rolling friction coefficient, radius of contact circle and normal stress, respectively. In order to represent irregular shape of coke, the rolling friction used in the present study might be different value for the original rolling friction.

Contact friction of coke is consisted of contact friction of

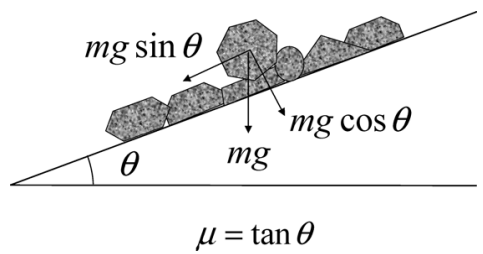

Fig. 3. Schematic representation of experimental method for measuring contact friction.

the material, roughness of surface and shape of piece. The contact friction measured from the actual coke includes the factors. The property of coke such as shape and roughness can not be measured. Therefore, combination of rolling and contact friction coefficient is used for representing the physical property of coke. The combination of the coefficients is derived the calculation of angle of repose.

\subsection{Measurement of Contact Friction Coefficient of Particle}

The contact friction coefficient used in the DEM simulation includes factor of shape, roughness and material. Thus, two measurements are carried out, (a) a piece of coke was placed on a coke bed, and the coke bed is tilted until the piece of coke slide (Fig. 3) and (b) a polished surface of coke was put on another polished surface of that, and the coke is tilted until slide. The angles were measured. The contact friction coefficient $\mu$ is derived from the following equation;

$$
\mu=\tan \theta
$$

where $\mu$ denotes the angle measured in the experiment. The measurement had been run 10 times, and the average was derived. 1.57 and 0.76 were obtained for friction coefficient by the measurement (a) and (b), respectively. The value of (a) includes the factors of shape and roughness of surface, (b) is not including the factors. The contact friction coefficient should be less than the value of (a) and more than that of (b), namely contact friction coefficient is a value between 0.76 and 1.57 .

The contact friction coefficient between coke and firebrick also was measured. A piece of coke or a polished surface of coke surface were put on flat surface of a fire brick and the angles of sliding were measured. From the piece of coke and flat surface of that, friction coefficients were obtained as 0.69 and 0.55 , respectively. Compared to the friction between coke and coke, the difference between two measurement for that between coke and wall is small. Therefore the average value namely, 0.62 was used in following simulation as the contact friction coefficient between coke and wall.

In order to estimate the influence of contact and rolling friction coefficient on the solid motion, calculations are carried out with combination of 1.0, 2.5 and 5.0 in rolling friction coefficient $\alpha$ and $0.76,1.0,1.25$ and 1.57 in contact friction coefficient $\mu$. Condition of simulation is listed in Table 1. The velocity distribution of particle in the vertical section on tuyere by the DEM simulation is shown in Fig. 4. The velocity of particle is calculated for each $0.02 \mathrm{~s}$. The velocity and position of particles were plotted for $5 \mathrm{~s}$. Circles demote the particle and the color represents scalar ve- 
Table 1. Physical constant for estimation of combination of frictions used in DEM calculation.

\begin{tabular}{lcc}
\hline Young's modulus & $6.0 \times 10^{9}$ & {$[\mathrm{~Pa}]$} \\
Poisson's ratio & 0.21 & {$[-]$} \\
Frictional coefficient $(\mathrm{p}-\mathrm{p})$ & $0.76 \sim 1.57$ & {$[-]$} \\
Frictional coefficient $(\mathrm{p}-\mathrm{w})$ & 0.62 & {$[-]$} \\
Rolling frictional coefficient & $1.0 \sim 5.0$ & {$[-]$} \\
Radius of particle & 10 & {$[\mathrm{~cm}]$} \\
Density of particle & $1100 \quad\left[\mathrm{~kg} / \mathrm{m}^{3}\right]$ \\
Time step & $1.0 \sim 5.0 \times 10^{-5}$ & {$[\mathrm{~s}]$} \\
\hline p-p: Particle and particle & \multicolumn{3}{c}{} \\
p-w: Particle and wall & \multicolumn{3}{l}{}
\end{tabular}

locity of each particle vector. Red and blue indicate high and low velocity. In order to decrease computation time, the motion in calculation is accelerated about 300 times. Therefore, the particle velocity calculated by DEM was converted to the actual particle velocity, because the time scale was extensively reduced in DEM. In Fig. 4, the particle velocity shows the actual value in the blast furnace.

Here, some active particles as shown in red color can be seen in the center of the blast furnace. Since the solid motion changes from vertical to oblique flow over the deadman, unstable motion occur frequently near center of blast furnace. However those are out of sight for the object of present simulation.

In every results, the boundary of deadman and stream of particle in solid motion is not clear, and the velocity varies gradually around boundary of them. The ununiformity of velocity increases with an increasing in the contact friction coefficient. Meanwhile, total motion of particles does not vary with varying the contact friction. Decreasing rolling friction parameter causes a wider flow of particle over the tuyere. The flow becomes narrow and active with increasing in the rolling friction. It is shown that both of contact and rolling friction have influence on the solid motion.

Figure 5 shows average velocity of all particles in volume from 0 to $5 \mathrm{~m}$ over tuyere level with various contact friction coefficient and constant rolling friction; $\alpha=2.5$. In Fig. 5, the average particle velocity and the time scale represent the hypothetical values directly calculated in DEM. The time cycle of oscillation does not vary with varying the contact friction coefficient, the variation of magnitude of fluctuation increases with an increasing in friction coefficient. Average velocity of all particles in the area of blast furnace with various rolling friction coefficient with constant contact friction; $\mu=1.0$ is shown in Fig. 6. The variation of magnitude of fluctuation becomes unstable with an increasing rolling friction coefficient. The increasing of contact and rolling frictions causes the solid motion unstable.

From the above results, although the influence of contact and rolling friction coefficient can be noticeable on the solid motion, it is difficult to determine the appropriate values for them. Some additional procedures were taken to set the parameters suitable for the blast furnace.

\subsection{Derivation Rolling Friction Coefficient}

Angle of repose of particle can be represented with DEM for various contact and rolling friction coefficients. The angle of repose for the coke bed in the top of blast furnace is 32 degree. ${ }^{16)}$ Combination of contact and rolling friction coefficient that represent 32 degree in the angle of repose was searched.

The $10^{5}$ of particles in $10 \mathrm{~cm}$ diameter were pleased as cylindrically in air. An edged disk with $7 \mathrm{~m}$ diameter is pleased below the particles. The gravity on the particles was activated at beginning of the simulation, and the particles will start to fall down in naturally. Some of particle would be stable on the disk, and others fall down from it. After all of the particle become steady in the motion, the angle of repose of the particle will be obtained. Contact and rolling friction coefficients were varied in the range of $\alpha=1.0-5.0$ and $\mu=0.76-1.57$, respectively. The results of simulation are shown in Fig. 7. The angle of repose increases with increasing in the contact and rolling frictions. Minimum value of that is about 25 degree with $\mu=0.76$, $\alpha=1.0$, and maximum is about 45 degree with $\mu=1.57$, $\alpha=5.0$. Combinations of the frictions in the range from 30 to 35 degree are $\mu=0.76$ and $\alpha=5.0, \mu=1.0$ and $\alpha=2.5$, $\mu=1.25$ and $\alpha=1.0, \mu=1.25$ and $\alpha=2.5$, and $\mu=1.57$ and $\alpha=1.0$. It is already written in section 3.2 that 0.76 and 1.57 as the contact friction coefficient are too small and large, respectively. Therefore, the combination of friction parameters with $\mu=1.0$ and $\alpha=2.5$ is employed in the simulation in the following sections.

\subsection{Influence of Young's Modulus on Solid Motion in Packed Bed}

To perform smoothly the practical simulation, the time step for the calculation is an important factor. The time step of the calculation is constrained by the physical properties of the particles in DEM calculation. Since the appropriate adjustment of the Young's modulus possibly causes the reduction in computation time without deteriorating simulation accuracy, ${ }^{8}$ the influence of Young's modulus on the solid motion is evaluated for various hardness in the range of 6.0-0.06 GPa. As described above, the hardness of coke before reaction at room temperature is reported to be 5-10 GPa. ${ }^{17)}$ DEM calculation was carried out to examine the effect of Young's modulus on the solid motion in the vicinity of the raceway. In order to prevent the clogging around raceway, the discharging velocity was set to 200 particles for every second.

The velocity of particle in the vertical section intercepting center of blast furnace and one tuyere is shown in Fig. 8. Ellipsoid space at left bottom side represents raceway. According to the results, the particle in the upper part of raceway moves very fast for every condition. Especially, in the case of (c), the high velocity area is concentrated on over raceway. The particle velocity distributions in (a) and (b) are similar to each other. The low velocity area can be observed in the right side of raceway to center of the blast furnace. This area represents deadman zone.

Figure 9 shows the average velocity of all particles from $5 \mathrm{~m}$ over and $1 \mathrm{~m}$ below the tuyere level with various Young's modulus. Active and inactive periods are observed alternately for all conditions. Length of periodical fluctuation increases and magnitude of the fluctuation decreases with a decreasing in the hardness. The fluctuation of 6 and $0.6 \mathrm{GPa}$ is relatively similar for each other. In the condition of low Young's modulus of $0.06 \mathrm{GPa}$, magnitude of the fluctuation decreases. On the other hand, the calculation time can be much improved in 10 times with using particles of 

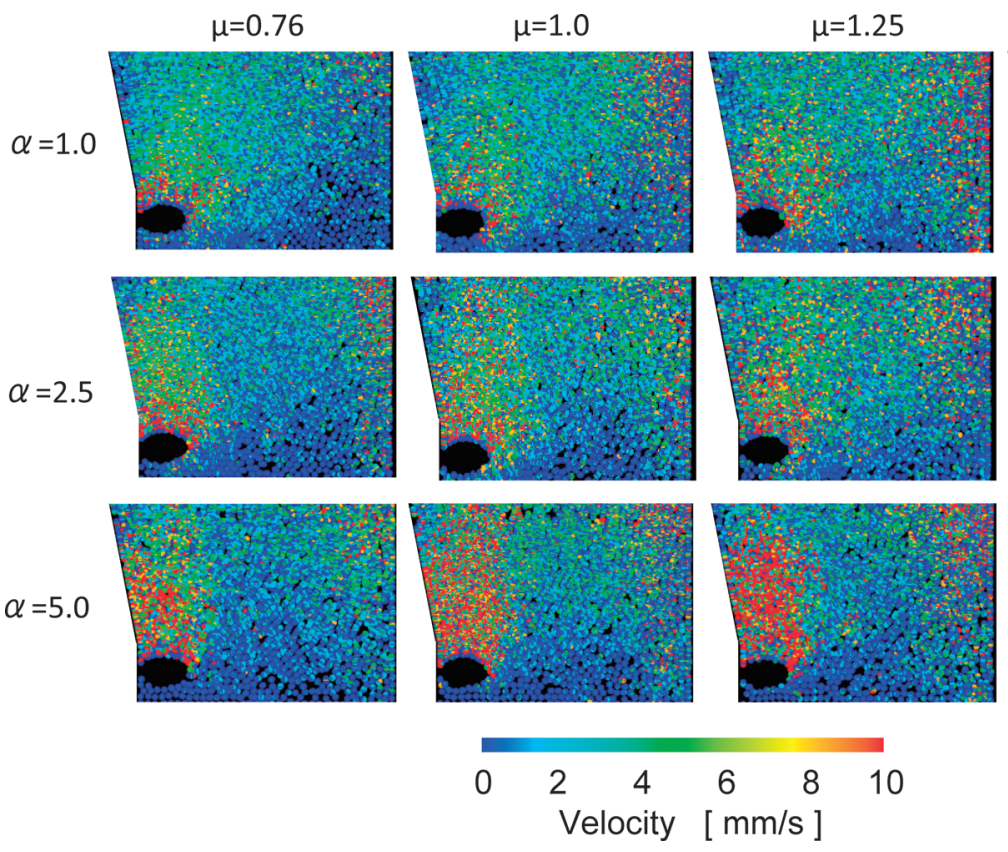

Fig. 4. Calculated particle velocity with various contact friction coefficients $\mu$ and rolling friction coefficients $\alpha$.
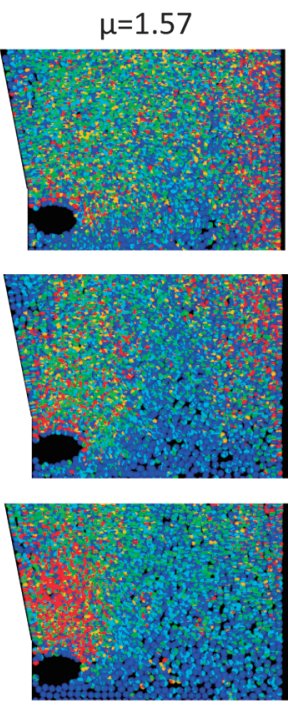

\section{(c) $0.06 \mathrm{GPa}$}

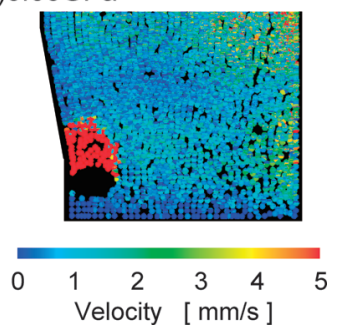

Fig. 8. Velocity of particle in front of tuyere with various Young's modulus.

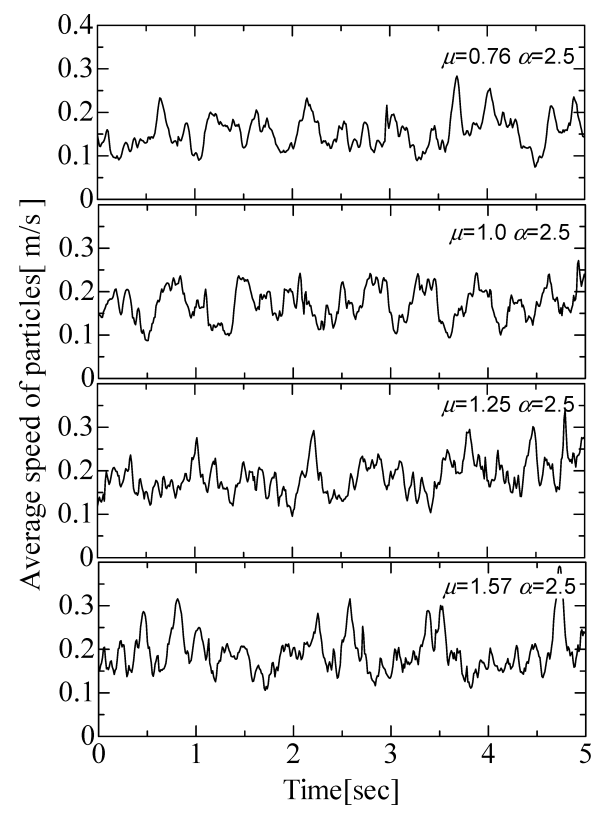

Fig. 5. Average velocity change of particle with various contact friction coefficient.

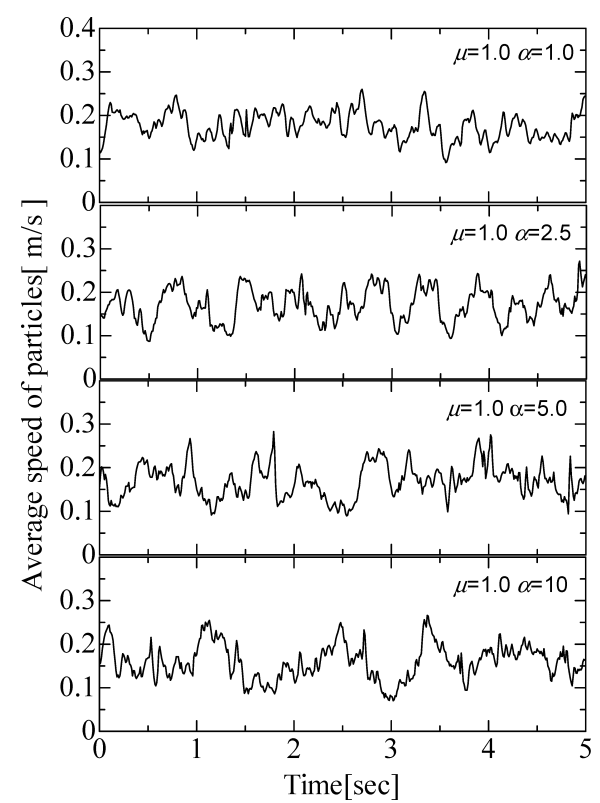

Fig. 6. Average velocity change of particle with various rolling friction coefficient.
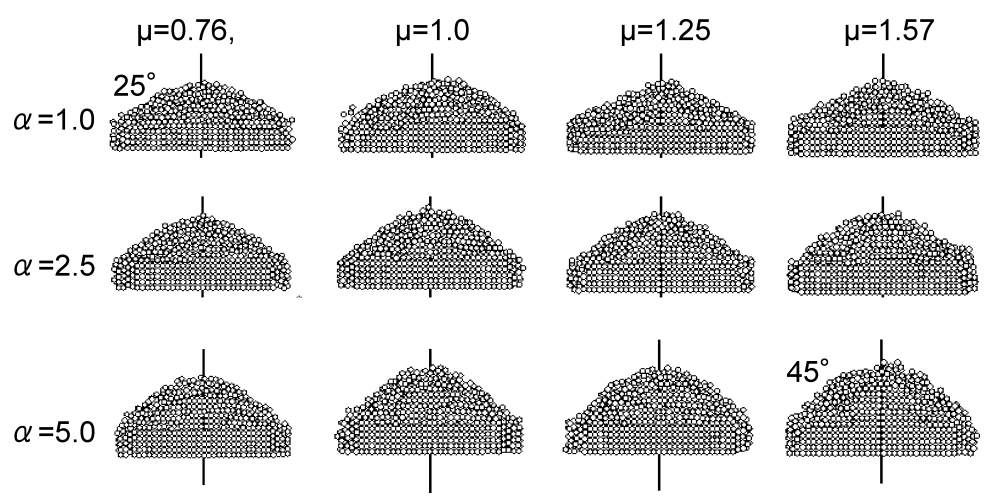

Fig. 7. Angle of repose for particle $20 \mathrm{~cm}$ in diameter with various contact and rolling friction coefficients on the $7 \mathrm{~m}$ disk. 




Fig. 9. Average velocity of particle with various Young's modulus.

Table 2. Physical constant used in DEM calculation.

\begin{tabular}{lcc}
\hline Young's modulus & $6.0 \times 10^{9}$ & {$[\mathrm{~Pa}]$} \\
Poisson's ratio & 0.21 & {$[-]$} \\
Frictional coefficient $(\mathrm{p}-\mathrm{p})$ & 1.0 & {$[-]$} \\
Frictional coefficient $(\mathrm{p}-\mathrm{w})$ & 0.62 & {$[-]$} \\
Rolling frictional coefficient & 2.5 & {$[-]$} \\
Radius of particle & 10 & {$[\mathrm{~cm}]$} \\
Density of particle & 1100 & {$\left[\mathrm{~kg} / \mathrm{m}^{3}\right]$} \\
Time step & $5.0 \times 10^{-5}$ & {$[\mathrm{~s}]$} \\
Discharging rate & 200 & {$[1 / \mathrm{s}]$} \\
\hline p-p: Particle and particle & & \\
p-w: Particle and wall & &
\end{tabular}

$0.06 \mathrm{GPa}$. Although acceleration of calculation can be performed by the low Young's modulus, the accuracy to represent the ununiform solid motion nearby the raceway as the subject of this study is not sufficient. Accordingly, in the following simulation, $6 \mathrm{GPa}$ was employed for Young's modulus.

\section{Analysis on the Solid Motion in the Vicinity of the Raceway}

\subsection{DEM Calculation for the Vicinity of Raceway}

Simulation of solid motion around raceway is carried out by DEM. This study focused on the shape and arrangement of the raceway, because the ununifromity in this region became noticeable in the large blast furnace. The condition of calculation is listed in Table 2. The shape and depth of raceway are naturally formed by the condition of blast gas in the actual blast furnace. In order to clarify the ununiformity of solid motion in the lower part, the intentional influence of the race way condition on the solid motion, namely, variation of shape, and interval between themselves were examined by DEM.

\subsection{Motion of Coke in the Front of Tuyere}

Figure 10 shows the calculated particle velocity distributions in the vertical section and the horizontal cross sections at $4-4.5 \mathrm{~m}, 3.0-3.5 \mathrm{~m}, 2.0-2.5 \mathrm{~m}, 1.0-1.5 \mathrm{~m}$ and $0-0.5 \mathrm{~m}$ over the tuyere level, respectively. The active particles as shown by red color are concentrated in the upper part of raceway. The influence of the raceway in the hori- zontal cross section can be clearly observed in the range of $3 \mathrm{~m}$ from the wall at $1.0-1.5 \mathrm{~m}$ and $0-0.5 \mathrm{~m}$ over the tuyere level. Totally, the velocity difference across the horizontal cross section can be recognized especially within $2.5 \mathrm{~m}$ over the tuyere level. Although the boundary of deadman is not clear, the stagnant zone corresponding the dead man can be observed in the central part at tuyere level. In the past, some experiments on the deadman shape have been performed by the cold model. ${ }^{18,19)}$ According to these results, the deadman shape can be represented by the slip line based on the plastic theory and the moving and stagnant regions can be clearly divided by slip line. In the lower part of the actual blast furnace, since the packed material consist of granular coke particles, it is estimated that solid flow field is difference from conventional plastic theory.

In the case of (c), namely, at $2.0-2.5 \mathrm{~m}$ level over the tuyere, the velocities of particle are distributed almost uniformly in circumferential direction compared with (d) and (e). The particle velocity distirubution become immediately uniform with increasing in the distance from tuyere level. The ununiform distribution of velocity of particles in the circumferential direction is limited only in upper part of the raceway with in $2 \mathrm{~m}$ range.

\subsection{Influence of Raceway Shape on Solid Motion}

Firstly, a case in which depth of the raceway enlarged from 1.5 to $3.0 \mathrm{~m}$ was simulated. The results of simulation are shown in Fig. 11. The region of deadman with stagnant particles become lower with increasing the depth of raceway. Compared to the reference condition shown in Fig. 10, the region of faster particles on the upper side of raceway becomes wide and shifts to the center part. The area of faster particle on the wall of the blast furnace is lower than that of the reference condition. The ununiform distribution of velocity of particle in circumferential direction is not observed. Since increasing raceway depth causes increasing the active area, therefore the region of deadman decreases in the height. Active streams are seen at upper wall side and center side of raceway.

The influenc of variation of the angle of tuyere is shown in Figs. 12(a) and 12(b) are angle of raceway varyed with 10 degree upward and downward, respectively. The height of deadman slightly changes with varying in the angle of raceway upward and downward, respectively. In both cases, the active particles are concentrated in upper part of raceway. The width of moving region with the risen raceway tends to slightly shrink. The effect of tuyere angle on raceway formation is reported. If the angle of tuyere was changed to upward, the active part of solid motion on raceway would become narrow. ${ }^{12)}$ In present result (a) in Fig. 12 , the tendency of solid motion on the raceway basically agrees with the previous literature.

\subsection{Influence of Interval between Raceway}

A condition that one of tuyere stopped for every two tuyeres is supposed. The center tuyere in the range of present simulation was cut off. The calculated results on the solid motion are shown in Figs. 13 and 14.

Figure 13(a) is particle velocity on vertical cross sections between the active tuyere and center of blast furnace, (b) is that on that between the stopped tuyere and center. Active 


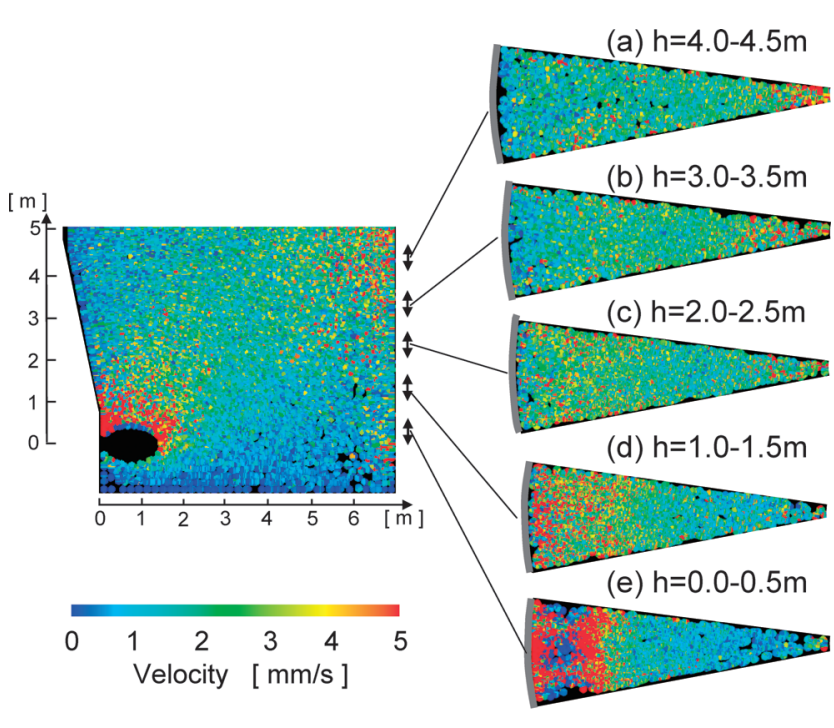

h: Height from tuyere

Fig. 10. Velocity distribution of particles in the vertical cross section on a tuyere and the horizontal section.

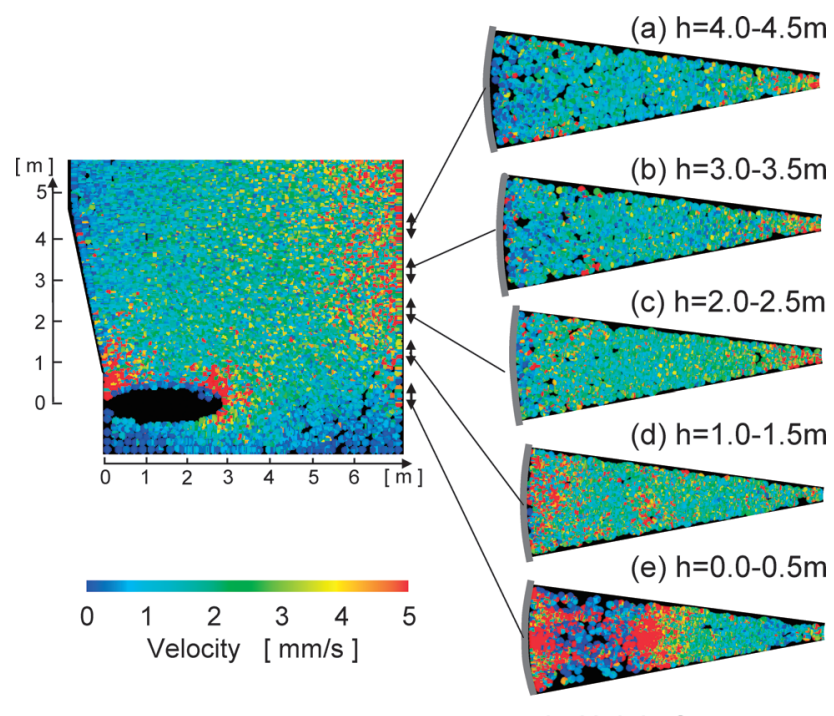

h: Height from tuyere

Fig. 11. Velocity distribution of particles in the vertical and horizontal sections with deep raceway.

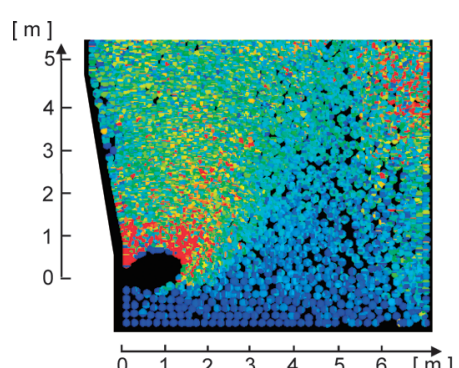

(a) Upward $10^{\circ}$



(b) Downward $10^{\circ}$

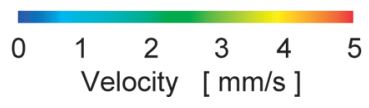

Fig. 12. Change of particle velocity in front of tuyere with various condition of raceway.

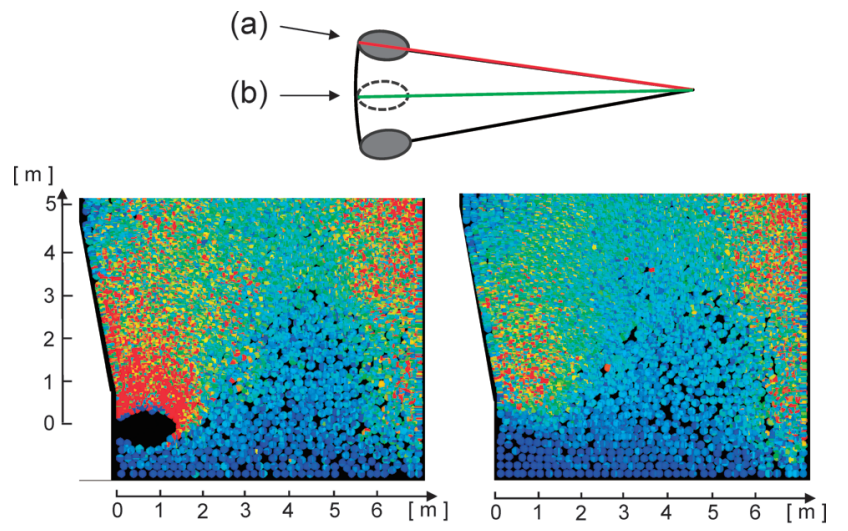

(a) On a tuyere

(b) Between tuyeres

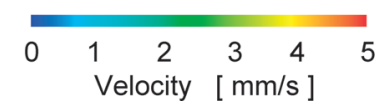

Fig. 13. Velocity of particle in front of tuyer with half number of tuyere. (a) On tuyere, (b) between tuyere.



(b) $h=3.0-3.5 \mathrm{~m}$

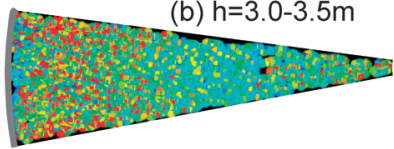

(c) $h=2.0-2.5 \mathrm{~m}$

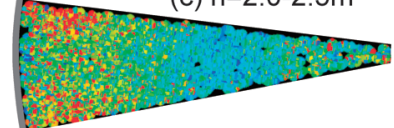

(d) $h=1.0-1.5 \mathrm{~m}$
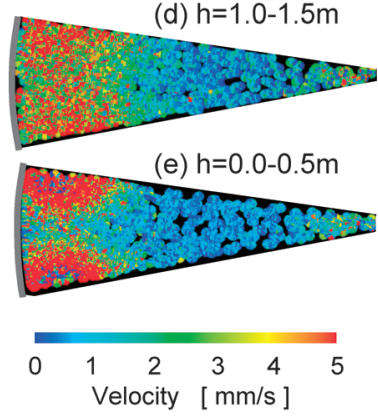

h: Height from tuyere

Fig. 14. Velocity distribution of particles in the horizontal section with half number of tuyere.

area on the upper side of raceway in (a) are small, meanwhile that in (b) is wide and moderate. The stagnant region corresponding to the deadman in (a) is larger than that in (b). The horizontal distributions of velocity of particle are shown in Fig. 14. In this raceway condition, the velocity of particle is not uniform ever at $3.0-3.5 \mathrm{~m}$ over the tuyere level compared with Fig. 10. The ununiformity in the circumferential and radial direction become remarkable. The shape of the stagnant zone becomes polygonal shape at tuyere level. The increasing interval of tuyeres seriously causes ununiform of solid motion in the blast furnace. Accordingly, the interval between the raceway is an important factor to assure the uniformity of the solid motion in the lower part of the blast furnace. 


\section{Conclusions}

Mathematical analysis of solid motion in the vicinity of raceway in the blast furnace was carried out by DEM. To represent the shape factor of particle and the solid motion, the optimum combination of contact and rolling friction was systematically introduced. The appropriate values was determined by the angle of repose calculated in DEM. The following results were obtained.

(1) To simulate the solid motion in the lower part of the blast furnace, the contact and rolling friction should be cautiously determined.

(2) Young's modulus of particle is an important factor to accelerate the calculation time in DEM, however, the actual value should be selected for the lower part in the blast furnace where the active and stagnant zone coexist.

(3) The influence of raceway in the vertical direction is limited to the region of $2 \mathrm{~m}$ from the tuyere level. The angle of the raceway has little influence on the height of deadman the motion in upper part of raceway.

(4) Increasing the depth of raceway causes that the region of faster particles on the upper side of raceway becomes wide and shifts to the center part and the height of deadman decreases remarkable.

(5) The influence of interval on the solid motion is significant. The ununiform zone tends to expand by the stoppage of tuyere.

Totally, by the application of DEM, the influence of raceway condition which can not be directly observed in the actual blast furnace can be simulated three-diminsionally.

\section{REFERENCES}

1) J. A. Castro, H. Nogami and J. Yagi: ISIJ Int., 42 (2002), 44.

2) H. Nogami, M. Chu and J. Yagi: Comput. Chem. Eng., 29 (2005), 2438 .

3) T. Ariyama, R. Murai, J. Ishii and M. Sato: ISIJ Int., 45 (2005), 1371.

4) P. A. Cundall and O. D. L. Strack: Geotechnique, 29 (1979), 47.

5) T. Nouchi, T. Sato, M. Sato and K. Takeda: Tetsu-to-Hagané, 92 (2006), 955.

6) K. Nakano and H. Yamaoka: Tetsu-to-Hagané, 92 (2006), 939.

7) H. Mio, S. Komatsuki, J. Hidaka, M. Kadowaki, S. Matsuzaki and K. Kunitomo: CAMP-ISIJ, 21 (2008), 901.

8) S. Ueda, H. Nogami, J. Kano and T. Ariyama: Proc. of Recent Progress on Mathematical Modeling in Ironmaking 2008, ISIJ, Tokyo, (2008), 146.

9) A. T. Adema, Y. Yang, and R. Boom: Recent Proc. of Progress on Mathematical Modeling in Ironmaking 2008, ISIJ, Tokyo, (2008), 130.

10) H. Takahashi and N. Komatsu: ISIJ Int., 33 (1993), 655.

11) K. Nozawa, T. Kamijo and M. Shimizu: Tetsu-to-Hagané, 81 (1995), 882.

12) M. Sawayama, Y. Matsui and Y. Yamagata: CAMP-ISIJ, 17 (2004), 136.

13) H. Takahashi, H. Kawai, T. Fukui, Y. Matsumoto and Y. Matsui: Tetsu-to-Hagané, 93 (2007), 615.

14) Y. Matsui, M. Tanaka, M. Sawayama, S. Kitano, T. Imai and A. Goto: Tetsu-to-Hagané, 92 (2006), 932.

15) T. Kawaguchi, S. Nishi, T. Tanaka and Y. Tsuji: 1993 Nendo Syunki Kenkyuu Happyoukai Koen Yoshi Syu, Soc. Powder Technol. Jpn., (1993), 106.

16) H. Nishio, T. Ariyama and M. Sato: Tetsu-to-Hagané, 73 (1987), 1527.

17) ISIJ and JSPS 54 Committee (ed.); Physical can Chemical Data Book for Iron- and Steelmaking, Ironmaking, (2005), 66.

18) T. Sato, M. Miyakowa, K. Takeda and H. Itaya: CAMP-ISIJ, 6 (1993), 887.

19) M. Shimizu, A. Yamaguchi, S. Inaba and K. Narita: Tetsu-toHagané, 68 (1982), 936. 